\title{
Effect of Behaviour Change Communication on Metabolic Syndrome and Its Markers among Ethiopian Adults: Randomized Controlled Trial
}

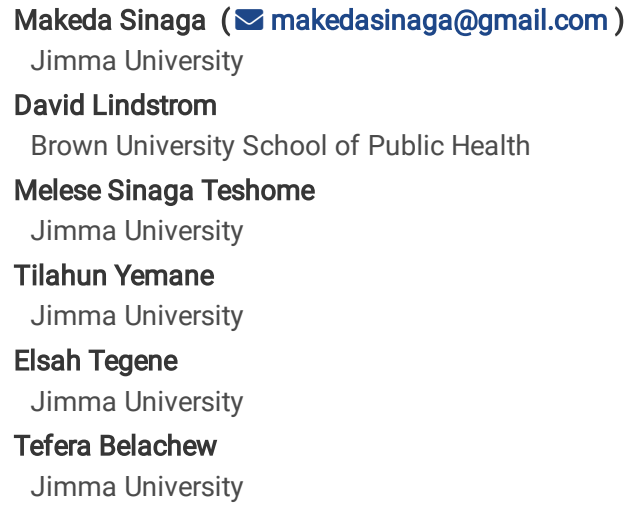

Research

Keywords: Metabolic syndrome, behaviour change communication

Posted Date: November 11th, 2020

DOl: https://doi.org/10.21203/rs.3.rs-20451/v2

License: (c) (i) This work is licensed under a Creative Commons Attribution 4.0 International License. Read Full License 


\section{Abstract}

Background: Metabolic syndrome (MetS) is a global public health problem with dire consequences on health, social and economic development. In Ethiopia although MetS has been increasing since the past few decades, there is no study that evaluated the effect of interventions. This study aimed to assess the effect of nutrition behaviour change communication on MetS and its markers.

Methods: An individually randomized controlled trial was conducted using a parallel design among Ethiopian adults working in Jimma University from of September 1, 2015 to January 15, 2016 for the intervention group. A sample size of 230 was calculated using GPower 3.0 assuming an effect size of 0.4 , margin of error of 0.05 , power of $81 \%$, with an intervention to control ratio of 1 . The eligibility criteria include: not having any physical disability and having baseline data.. Study population was randomly selected from eligible population $(n=704)$ and allocated into intervention ( $n=115)$ and controls $(n=115)$ groups using simple randomization method. The intervention arm was given behaviour change communication using power point presentation, facilitated group discussion on MetS and effective dietary and life style behaviours every month for three months. An Amharic language brochure was also given after the first training and a text message reminder about key behaviours was sent to each individual every two weeks. Data on background characteristic, anthropometry, and clinical parameters and blood samples were collected by trained data collectors in the Nutrition and Dietetic Laboratory of Jimma University. The laboratory analyses were done in Mettu Karl Hospital for lipid profiles and in JUCAN project laboratory for fasting blood sugar. Primary outcomes of the study were metabolic syndrome and its components. Difference in the differences of metabolic syndrome components between baseline and endline (end of intervention) were compared by the intervention status. Multivariable linear regression models were fitted to isolate independent predictors of difference in differences of metabolic syndrome components. A multivariable logistic regression model was used to identify preditors of MetS at the end line.

Results: Overall, there was a significant difference $(\mathrm{P}<0.001)$ in the prevalence of MetS between intervention $(11.6 \%)$ and control groups $(37.5 \%)$ on the end line survey. On multivariable logistic regression analyses, control groups were 8.5 times more likely to have MetS compared to intervention groups (AOR=8.53, $95 \% \mathrm{Cl}: 3.60,20.21, \mathrm{P}<0.001)$. There was a significant mean difference in differences in most components of metabolic syndrome and other lipid profiles except HDL $(P=0.717)$ in the intervention group. The mean difference in differences in waist circumference was $6.3 \mathrm{~cm}(P<0.001)$, while that of systolic blood pressure (BP) and diastolic BP were $6.1 \mathrm{mmHg}(P<0.001)$ and $3.6 \mathrm{mmHg}(P=0.001)$, respectively. Likewise the difference of differences between intervention and control groups was $30.7 \mathrm{mg} / \mathrm{dl}(P<0.001)$ for T.Cholestrol, $55.5 \mathrm{mg} / \mathrm{dl}(P<0.001)$ for triglycerides, $21.9 \mathrm{mg} / \mathrm{dl}(P=0.015)$ for LDL and 22.2 mg/dl $(P<0.001)$ for fasting blood sugar. Further multivariable linear regression analyses showed that after adjusting for many variables, there was a significant difference in difference between intervention groups in the components of MetS. For the intervention group the mean difference in differences was $6.1 \mathrm{~cm}(\beta=6.1, P<0.001)$ for waist circumference and $4.2 \mathrm{~mm} \mathrm{Hg}(\beta=4.2, P<0.05)$ for diastolic blood pressure and $6.5 \mathrm{mmHg}(\beta=6.5, P<0.001)$ for systolic blood pressure compared with controls. Similarly, the mean difference in differences was higher in the intervention group by $19.9 \mathrm{mg} / \mathrm{dl}(\beta=19.9, P<0.05)$ for FBS, $57.5 \mathrm{mg} / \mathrm{dl}$ for TG $(\beta=57.5, P<0.05), 24.40 \mathrm{mg} / \mathrm{dl}$ for $\operatorname{LDL}(\beta=24.4, P<0.05)$ and $30.9 \mathrm{mg} / \mathrm{dl}$ for T.Cholestrol $(\beta=30.9, P<0.001)$. This trial is retrospectively registered on $P a n$ African Clinical Trial Registration with unique identification number of PACTR202003465339638.

Conclusion: The study demonstrated that nutrition and life style behaviour change communication has a significant positive effect in reducing metabolic syndrome and its components. Although the study was conducted in an institutional set up, the results imply that enhancing such an interevention have a great potential to curb the emerging burden of chronic non-communicable diseases in Ethiopia. Future research should examine how sustainable such behaviour changes are using a community based study.

\section{Introduction}

Since few decades back, the burden of metabolic syndrome and chronic non-communicable diseases is emerging in developing countries at an alarming rate (1-2). Recent evidence shows that consequent to the globalization, change in dietary pattern and decline in physical activity levels, the magnitude of overnutrition is escalating on top of high prevalence of undernutrition leading to a double burden in sub-Saharan Africa (3-4).

The global prevalence of non-communicable diseases (NCDs) is on the rise, with the majority of the increase occurring among populations in developing countries (5). In Sub-Saharan Africa (SSA) where Ethiopia is situated, although infectious diseases still cause the majority of mortality (69\% of deaths), chronic non-communicable diseases such as cardiovascular disease, diabetes mellitus (DM), chronic respiratory disease and cancers, contribute nearly a quarter of deaths (6). This picture is changing as SSA is undergoing an epidemiological transition with a rapidly increasing burden of chronic noncommunicable diseases and associated mortality. In SSA, NCDs are projected to surpass infectious diseases (which are typically endemic to developing countries) by 2030 (5). As the prevalence of chronic non-communicable diseases is increasing, the interface between CNCDs and infectious diseases is becoming clearly apparent implying the need for intervention strategies that can address both problems. For instance, an increasing prevalence of diabetes may hinder efforts for tuberculosis control, increasing the number of susceptible individuals in populations where tuberculosis is endemic, and making successful treatment harder (3-4). On the other hand, the high prevalence of HIV infection in developing countries, especially in sub-Saharan Africa and concomitant anti-retroviral therapy leads to an upsurge of MetS (7-8).

Evidence shows that Ethiopia is having the burden of MetS and mortality from chronic non communicable diseases that are linked to overnutrition and life styles changes. Prevalence of MetS was reported to be $14.0 \%$ in men and $24.0 \%$ in women using IDF criteria; while individual components are prevalent among an apparently healthy working population in Ethiopia (9-10).

These findings indicate the need for evidence-based health promotion and disease prevention programs. Several studies in different countries demonstrated that varying levels of life style change interventions can reduce/reverse MetS (11-12). Another study showed that delivery of a structured group education programme to individuals with MetS improved management of cardiovascular and diabetes risk factors (11). However, these issues were not documented in Sub-Saharan Africa in general and in Ethiopia in particular. . 
Although the magnitude of MetS and chronic non communicable diseases is increasing in Ethiopia, there is no any organized public health intervention to prevent the occurrence of these problems and their risk factors. The health care system has limited itself to treating full-blown cases of MetS and its components. There no intervention that is underway to address this emerging problem. Studies elsewhere, had demonstrated that dietary intervention can prevent MetS (13-14). The effectiveness of interventions on MetS has not been evaluated in Ethiopian set up. The aim of this study was to evaluate the effect of nutrition and life style behaviour change communication (BCC) intervention on MetS and its markers.

\section{Methods And Materials Study Area and Period}

The study participants were recruited from Jimma University, which is a public higher educational institution established in December 1999. Jimma Town is $357 \mathrm{~km}$ southwest of Addis Ababa. The university has two institutes and six colleges encompassing a total of 1341 academic and 5444 administrative staffs. Evidences show that components of metabolic syndrome such as diabetes mellitus, hypertension and cardiovascular problems are common in the working population (9-10).

Trial design: An individually randomized controlled trial using a parallel design was employed to determine the effect of nutrition and life style behavior change communication (BCC) on MetS and its components.

Participants. Administrative and academic staffs of Jimma University who were involved in the baseline survey $(n=704)$ for developing anthropometric cutoffs (15) were eligible for enrolment into the study. Those who have physical disability including deformity (Kyphosis, Scoliosis), pregnant women, limb deformity that prevents standing erect were excluded.

Sample size. A sample size of 230 was calculated using Gpower 3.0 software assuming an effect size of 0.4 for the mean difference in differences of fasting blood sugar (the commonest component of MetS), margin of error of 0.05 , power of $81 \%$, with an intervention to control ratio of 1 and adding 26 for loss to follow up. FBS was used for sample size calculation as it gave the largest sample to have adequate power.

Randomization: The sample was randomly selected from eligible population and allocated to intervention group (those exposed to nutrition and life style behavior change communication) and the control group (those who did not receive any intervention). A simple randomization was done to allocate participants to the intervention $(n=115)$ and control $(n=115)$ arms using ENA Smart software.

Intervention: Six months after baseline data collection, the behavioural change communication intervention continued for three months starting from second half of September, 2015 and up to December 30, 2015. To avoid information contamination the end line data were collected in the first half of September 2015 , from the control group and from December 30 to January 15, 2016 for the intervention group. The intervention group was given a face to face behaviour change communication through different strategies including power point presentation for a group of 20 people and facilitated group discussion using evidence on real examples of cases with metabolic syndrome and effective dietary and life style behaviours. The training was delivered every month for three months in Jimma University by the research team members including senior nutritionist, cardiologist, and senior nurses. Each month, the training was given in morning and afternoon sessions for three days with each session lasting for four hours. Each of the intervention group members was given a two page Amharic language brochure to take home after the first training. The study subjects were also reminded the key mottos of the behaviours emphasized during the training through text messages every two weeks, while the control group received nothing before data collection (Table 1). The key messages included : " your menu should be colourful, avoid the three whites including: fat, sugar and salt, have a diversified diet, aerobic exercise, drink plenty of water, avoid sources trans fats, avoid smoking, avoid khat chewing, avoid unsafe intake of alcohol ( $\geq 2$ drinks per day), have a quality and adequate sleep and avoid sitting for long time", After the end line data were collected, similar information was given to the control group.

Compliance: Compliance to the intervention was measured through checking the attendances of the monthly training sessions, the number of reminder text messages sent to each person every two weeks and the number of intervention participants who receieved the two page brochure summarizing the training. All the training was given according to the protocol except that two paratcipants missed one and two training sessions.

Outcomes: Primary outcomes of the study are metabolic syndrome and its components including: waist circumference, systolic and diastolic blood pressures, fasting blood sugar, triglyceride levels, high density lipoproteins, total cholesterol and low density lipoproteins. Data collectors who did all anthropometric, clinical parameters measurements and laboratory technologists who did the blood sample analyses were blinded.

\section{Measurements}

This study was conducted in accordance with WHO's Stepwise (STEPs) approach for non-communicable disease (NCD) surveillance(16), which is characterized by the use of questionnaires to capture data on risk factors (Step 1): simple physical measurements (Step 2): and biochemical measurements (Step 3). The STEPs questionnaire was supplemented with additional questions to gather context specific data in the study area. The questionnaire was used to collect data regarding the general socio-demographic characteristics of the population including: age, sex, and education level. Questions included in the behavioural risk factors such as tobacco, alcohol, physical inactivity and Khat consumption (a natural stimulant with amphetamine-like effects commonly used for social recreation in Ethiopia) (17). Experienced research nurses were trained for five days on the contents of the questionnaire, ethical issues and on data collection procedure. All blood sample collections, questionnaire based interviews, anthropometric measurements and blood pressure measurements were done in the laboratory of Department of Nutrition and Dietetics of Jimma University. 
Body composition: Body fat percent (adiposity) was determined both at baseline and end line using different anthropometric indices: Body Mass index (BMI) and Waist Circumference (WC). Baseline Body fat percent was measured using air displacement plethysmography (ADP) (life Measurements) following standard procedures (15). Weight was measured with a solar powered scale which was accurate to 100 grams (Model 871, Seca, Germany). Height was measured with an adjustable portable stadiometer which was accurate to $0.1 \mathrm{~cm}$. Waist circumference was measured with a fixed tension tape, at the midpoint between the lower costal margin at the mid-clavicular line and anterior-superior iliac crest (18) in a private place with no clothing on the upper part of the body. To ensure the data quality, Calibration and validation of anthropometric equipments and standardization of anthropometric measurers was done and a coefficient of variation of $<3 \%$ was taken as acceptable.

Blood pressure, Lipid Profiles and Fasting blood Glucose. Three blood pressure measurements were taken after individuals had rested for 5 minutes for the first measurement and with a difference of five minutes between successive measurements. In accordance with the WHO recommendation the mean systolic and diastolic BP measurements were considered for analyses. A five $\mathrm{ml}$ blood samples was collected from each individual in the morning after overnight fasting using proper sanitation and infection prevention techniques. Serum was used for the measurement of triglycerides (TG), total cholesterol (TC), highdensity lipoprotein cholesterol (HDL), low-density lipoprotein cholesterol (LDL), glucose concentrations. Details of the methods are published elsewhere (15)

For the end line data, a five $\mathrm{ml}$ blood specimen was collected by senior medical laboratory technologist and the serum was separated from the whole blood within 30 minutes and transferred to Nunc tubes and stored in $-20^{\circ} \mathrm{C}$ refrigerator. After all the specimens were collected, the serum was packed with ice and transported to Mettu Karl Hospital laboratory for determination of lipid profiles using HumaStar 80 (Germany) following standard operating procedures. Fasting blood sugar was determined in Jimma University specialized hospital (JUSH) at JUCAN project laboratory using Humastar within two hours of collection.

\section{Statistical Analyses}

Data were doubly entered into Epidfata 3.0 and exported to SPSS for windows version 20 (Inc, Chicago, IL, USA) for cleaning and analyses. The data were cleaned for outliers and missing values before analyses. After excluding a total of six participants ( 3 interventions and 3 controls) due to loss to follow up and incomplete data (Figure 1) a final sample size of 224 participants (intervention=112 and control =112) was analyzed. As there were baseline differences in some variables beteen intervention and control groups, difference in differences was employed in all analyses for comparison of the intervention and control arms to determine the effectiveness of the intervention on MetS components. The end line measurements were subtracted from baseline measurements for both intervention and control groups and the differences in differences were compared using independent sample t-test and multivariable linear regression model were used for comparing mean difference in differences. Assumptions including normality, linearity and absence of multi-collinearity and homoscedasticity were checked using Q-Q plots and variance inflation factor.

For the differences in proportions between intervention and control groups at end line chi-square test was used. Multivariable logistic regression model was used to isolate independent predictors of metabolic syndrome at the end of the intervention. For the multivariable logistic regression, multicollinearity and model fitness were checked using standard error $<2.0$ and Hosmer Lemeshaw test $(P>0.05)$, respectively. Statistical significance was declared at $<0.05$.

\section{Operational Definition of Terms}

Intervention group - Randomly selected adults who were given nutrition and health life style behavior change communication for three months.

Control group - Randomly selected adults who were not given nutrition and health behavior change communication.

Duration of the intervention: The time during which the life style medication behavior changes communication was given to the intervention group (three months staring from the second half of September 2015 to the December 30, 2015).

Components of Metabolic syndrome based on IDF criteria (20) as follows:

- Raised TG level: > $150 \mathrm{mg} / \mathrm{dL}(1.7 \mathrm{mmol} / \mathrm{L})$, or specific treatment for this lipid abnormality

- Reduced HDL cholesterol: < $40 \mathrm{mg} / \mathrm{dL}(1.0 \mathrm{mmol} / \mathrm{L})$ in males and < $50 \mathrm{mg} / \mathrm{dL}(1.3 \mathrm{mmol} / \mathrm{L})$ in females, or specific treatment for this lipid abnormality.

- Raised blood pressure: systolic BP $\geq 130$ or diastolic BP $\geq 85 \mathrm{~mm} \mathrm{Hg}$, or treatment of previously diagnosed hypertension.

- Raised fasting plasma glucose (FPG) $\geq 100 \mathrm{mg} / \mathrm{dL}$ ( $5.6 \mathrm{mmol} / \mathrm{L}$ ), or previously diagnosed type 2 diabetes If above $5.6 \mathrm{mmol} / \mathrm{L}$ or $100 \mathrm{mg} / \mathrm{dL}$.

- Central obesity was defined as waist circumference $\geq 80$ for women and $\geq 94$ for men.

Metabolic syndrome (MetS) is defined in accordance with the IDF as presence of abdominal obesity and three or more MetS components described above (1920).

\section{Results}


Baseline background characteristics of the study participants are presented in Table 2 below. The mean ( \pm sd) age of the study participants were $36.9( \pm 10.0)$ years for intervention and $37.7( \pm 10.0)$ for control groups. The proportion of males and females was $50.9 \%$ and $49.1 \%$ for the intervention and $43.8 \%$ and $56.3 \%$ for control groups. The intervention and control groups were similar in terms of their baseline level of total cholesterol, triglyceride, systolic and diastolic blood pressures, body fat percent and body mass index. However, the intervention group had higher LDL (94.0 \pm 43$) \mathrm{mg} / \mathrm{dl} \mathrm{compared} \mathrm{to} \mathrm{84.6}( \pm 77.3) \mathrm{mg} / \mathrm{dl}$ for the controls. Likewise, the level of HDL was low in the intervention $(58.7 \pm 28.7) \mathrm{mg} / \mathrm{dl}$ group compared to the controls $(68.3 \pm 63.4) \mathrm{mg} / \mathrm{dl}$. Conversely, fasting blood sugar was slightly lower in the intervention group $(97.1 \pm 21.6) \mathrm{mg} / \mathrm{dl}$ compared with the control group $(102.4+39.6) \mathrm{mg} / \mathrm{dl}$.

In Table 3, comparison of levels of metabolic syndrome components and lipid profiles at baseline and end line was made and the differences in the differences between the baseline and end line values were compared by the intervention status. The results showed that there was a significant difference in differences in most components of metabolic syndrome and other lipid profiles except HDL $(P=0.717)$. The mean difference of differences in waist circumference was $6.3 \mathrm{~cm}(P<0.001)$, while that of systolic blood pressure $(B P)$ and diastolic $B P$ were $6.0 \mathrm{~mm} \mathrm{Hg}(P<0.001)$ and $3.6 \mathrm{~mm} \mathrm{Hg}(P=0.001)$, respectively. Likewise the difference of differences between intervention and control groups was $30.7(P<0.001)$ for $T$.Cholesterol, $55.5(P<0.001)$ for triglycerides, 21.9( $P=0.015)$ for $L D L$ and $22.2(P<0.001)$ for fasting blood sugar.

Further multivariable linear regression analyses showed that after adjusting for many variables, there was a significant difference in differences between intervention and control groups in the components of metabolic syndrome that are based on physical measurements. For the intervention group the mean difference in differences was $6.1 \mathrm{~cm}(\beta=6.1, P<0.001)$ for waist circumference and $4.2 \mathrm{~mm} \mathrm{Hg}(\beta=4.2, P<0.05)$ for diastolic blood pressure and $6.5 \mathrm{mmHg}$ $(\beta=6.5, P<0.001)$ for systolic blood pressure compared with controls. The other variable significantly associated with diastolic blood pressure was baseline body fat percent of the study participants. For a unit increase in baseline body fat percent, the mean difference in differences of diastolic blood pressure was lower by $2.0(\beta=2.0, \mathrm{P}<0.05) \mathrm{mmHg}($ Table 4$)$.

The results of another multivariable linear regression analyses presented in Table 5 showed that after adjusting background variables, the intervention group had high difference of differences in LDL, Triglycerides, T.Cholestrol and fasting blood sugar (FBS). The mean difference in differences was higher in the intervention group by $19.9 \mathrm{mg} / \mathrm{dl}(P<0.05)$ for FBS, $57.5 \mathrm{mg} / \mathrm{dl}$ for $T G(P<0.05), 24.40 \mathrm{mg} / \mathrm{dl}$ for $L D L(P<0.05)$ and 30.9mg/dl for T.Cholestrol $(P<0.001)$.

Other variables associated with LDL were sex and monthly income. The difference in differences was lower by $30.5 \mathrm{mg} / \mathrm{dl}(\beta=30.3, \mathrm{P}<0.01)$ for $L \mathrm{LL}$ among males. Conversely, those who had high income and medium income had higher difference in differences for LDL by $45.7 \mathrm{mg} / \mathrm{dl}(\beta=45.7, \mathrm{P}<0.01)$ and 37.9 $\mathrm{mg} / \mathrm{dl}(\beta=37.9, P<0.01)$, respectively. For T.Cholestrol, those in the high income and medium income category had higher mean difference in differences by $36.2 \mathrm{mg} / \mathrm{dl}(\beta=36.2, P<0.05)$ and $33.1 \mathrm{mg} / \mathrm{dl}(\beta=33.1, P<0.05)$, respectively. Similarly, males have significantly higher difference in differences of TG by 54.9 $\mathrm{mg} / \mathrm{dl}(\beta=54.9, P<0.01)$. Likewise, for a unit increase in base line fat mass the difference in differences of TG was higher by $2.12 \mathrm{mg} / \mathrm{dl}(\beta=2.12, P<0.01)$. Difference of the differences in FBS was significantly associated with sex and baseline body fat percent. Being male increased the difference in differences at the end line by $13.28 \mathrm{mg} / \mathrm{dl}(\beta=12.38, P<0.05)$. For a unit increase in baseline body fat percent, the difference in difference of FBS increased by $0.66 \mathrm{mg} / \mathrm{dl}$ $(\beta=0.66, P<0.001)($ Table 4$)$.

The results showed that in both intervention and control groups, small proportion of the study participants were free of any of the MetS components (13.4\% for intervention vs $5.4 \%$ for controls). Large proprtion of both intervention and control groups have atleast one or two of the metabolic syndrome components. Howver, there was a significant difference in the proportion of intervention and control groups with three or more metabolic syndrome componets(Figure 2).

Overall, there was significant difference $(\mathrm{P}<0.001)$ in the prevalence of metabolic syndrome between intervention $(11.6 \%)$ and control groups $(37.5 \%)$ at the endline, while there is no significant difference in the baseline survey (Figure 3). This difference between intervention and control groups at the endline survey was consistent across the different sexes (Figure 4).

The results of multivariable logistic regression showed that variables including: intervention, sex, age base line body fat percent were independent predictors of MetS. Control groups were 8.5 times more likely to have MetS compared to intervention groups (AOR=8.53, 95\% Cl: 3.60, 20.21, P<0.001). Males were 10.2 times more likely to have MetS as compared to females ( $A O R=4.71,95 \% \mathrm{Cl}: 2.60,39.84, \mathrm{P}=0.001)$. Similarly for one year increase in age the likelihood of having MetS was higher by $6 \%(\mathrm{AOR}=1.06,95 \% \mathrm{Cl}$ : 1.01, 1.11, $\mathrm{P}=0.029)$. Likewise, for a unit increase in baseline body fat percent, the odds of having MetS increased by $11 \%(\mathrm{AOR}=1.11,95 \% \mathrm{Cl}$ : 1.04, 1.18, $\mathrm{P}=0.001)$ (Table 6).

\section{Discussion}

The study demonstrated a significant positive effect of behaviour change communication implemented for three months on MetS and its components, which is consistent with a 12 week yoga-based lifestyle intervention among Indian adults with metabolic syndrome (21) and a 12 week life style education interventional in Thai adults (22). A systematic review of randomized controlled trials in different population groups also showed positive effect of life style modification interventions starting from 10 weeks duration (23). In this study, the likelihood of having MetS was 8.5 times higher among the control group after adjusting for background variables indicating the significance of lifestyle modification interventions in the prevention of MetS and related noncommunicable diseases. This finding is consistent with the report of meta analyses of randomized controlled trials that showed life style modification intervention were effective in resolving MetS and reducing the severity of related abnormalities including fasting blood glucose, waist circumference, systolic blood pressure (SBP) and diastolic blood pressure (DBP), and triglycerides in subjects with MetS $(12,13,24)$.

The positive results imply the need for adopting lifestyle modification programs in the management of MetS and its components (25-26). It was also reported that modifying diet together with frequent physical exercise can reduce the triglycerides concentration as well as SBD and DBP (24, 27, 28). The need for implementing effective lifestyle modifications to prevent MetS and its health consequences has been indicated $(24,29)$. 
Sex and age were other variables associated with metabolic syndrome. It was observed that males were 4.7 times more likely to have MetS as compared to females, which is consistent with other reports (30). For one year increase in age, the likelihood of MetS was higher by $6 \%$, which is similar to a report from elsewhere (31). The relationship between MetS components with older age and male sex has also been reported (32).

It was also observed that the intervention group has significantly $(\mathrm{P}<0.05)$ higher dereference in differences between baseline and end line surveys for serum levels of FBs, Triglycerides and T.cholestrol and higher levels of HDL compared to the control group. A similar finding was reported by studies from elsewhere $(24 ; 27,33)$. Likewise, the intervention group had a significant difference in differences in waist circumference similar to reports of studies elsewhere (34-35).

The results showed that intervention group the mean difference in differences was $4.2 \mathrm{mmHg}(\mathrm{P}<0.05)$ for diastolic blood pressure and $6.5 \mathrm{mmHg}(\mathrm{P}<0.001)$ for systolic blood pressure compared with controls. This finding is consistent with another study which showed that the mean diastolic blood pressure (DBP) and triglycerides decreased significantly in the intervention group in both sexes (36). A positive effect of life style modification on blood pressure has also been reported among Korean adults $(37,38)$.

It has been documented that interventions incorporating dietary, physical activity and other life style changes exerts beneficial effects on the various components of the MetS and improves overall survival $(13,24,27,28,29)$. However, interventions targeting life style changes have the potential to succeed only if they are executed early to offer strong evidence to substantiating the development of appropriate public policies $(14,23)$.

Baseline body fat percent of the study participants was significantly associated with diastolic blood pressure such that for one percent increase in baseline body fat percent the mean difference in differences in diastolic blood pressure was lower by $0.2 \mathrm{mmHg}(\mathrm{P}<0.05)$. This could be related the effect of high body fat percent on the cardiovascular system which minimizes the difference in the blood pressure changes. The effect of body fat percent on increasing blood pressure has been documented by other studies $(13,38,39$,$) .$

Multivariable linear regression analyses showed that the intervention has high difference of differences in LDL, Triglycerides, T.Cholestrol and fasting blood sugar (FBS). A similar positive effect of life style modification was reported on lipid profiles (40-41) and blood sugar level (42). It was also observed that the difference in differences was lower by $30.5 \mathrm{mg} / \mathrm{dl}$ for LDL among males compared to females. This indicates that at the end of the follow up period, the decrease in LDL cholesterol was lower among men. The relationship between gender and lipid profile is age dependent. At younger age men tend to have higher levels of LDL, while this relationship gets reversed during older age especially after menopause where women tend to have higher level of LDL( 43) implying the need for careful interpretation of this finding.

Similarly, participants who had high income and medium income had higher difference in differences for LDL and T.Cholestrol compared with those in lower income. Evidence shows that an increase in income without change in educational status was associated with poor lipid profiles (44). However, the positive association of income with differences in differences of LDL and T.Cholestrol could be due to the fact that income is highly associated with educational status in the study population (university staff), which in turn may affect the level of adherence to the behaviour change interventions(45).

The positive findings of the behaviour change communication observed in this study have wider practical implications for Ethiopia where both modifiable and non-modifiable risk factors for chronic non-communicable diseases are increasing from time to time while the commensurate preventive intervention are lagging behind. The non-modifiable risks factors include increased life expectancy to over 64 years (46) and history of high proportion of early life stunting (47-51). Early life stunting could generate a huge potential for emergence of epidemics of chronic non-communicable diseases due to organ stunting. It has been reported that early childhood malnutrition including during the fetal period leads to occurrence of chronic non-communicable diseases later in life (52). The modifiable risk factors include dietary transitions to more processed and low fibre high calorie diet and sedentary and motorized way of life (53-55). The positive effect of the intervention documented in these modifiable risk factors implies the need for enhancing such interventions using different strategies through the involvement of different sectors to curb the upsurge of non-communicable disease and associated consequences in the years to come.

The study employed an individually randomized controlled trial to generate empirical evidence on the effectiveness of intervention approaches, which could potential lead to information contamination. To minimize this, the end line data were collected from the control group earlier than the intervention group, which is not expected to have an effect in their dietary and other behavioural factors as the data from both groups was also collected in the same season. As this study was done among university staff who may be a group of highly motivated participants, the findings may not be generalizable to the community setup. However, the sample involved both academic and administrative staff including gardners,cleaners, guards who are closer in background characteristics to the community making the concern minimal. This study evaluated an intervention that lasted for three months. If it is integrated to the existing health system the cost incurred for purpose is insignificant. However, our study did not capture serial measurements of MetS and its components to come up with a suggestion on the minimum number of days required for such an intervention to bring about significant chnage, which is the limitaiuion of this study. However, three months is not also a long time given the chronic nature the metabolic changes. Future research should determine the minimum number of days required to have a significant effect on the outcome variables.

\section{Conclusions}

The study demonstrated that nutrition and life style behaviour change communication has a significant positive effect in reducing metabolic syndrome and its components. Although the study was conducted in an institutional set up, the results imply that enhancing such an intervention have a great potential to curb the emerging burden of chronic non-communicable diseases in Ethiopia. Future research should examine how sustainable such behaviour changes are using a community based study.

\section{Abbreviations}


ADP: Air Displacement Plethysmography; BMI: Body Mass Index; ROC: Receiver Operating Characteristics Curve; WC: Waist Circumference; WHR: Waist to Hip Ratio; WHtR: Waist to Height Ratio

\section{Declarations}

\section{Acknowledgements}

We appreciate Institute of Health, Jimma University for funding the study and JUCAN project and Mettu Karl Hospital for providing body composition analyses and laboratory facilities for lipid profiles analyses, respectively. We are also grateful the study participants for their willingness involve in the study.

\section{Funding}

The study was funded by Jimma University; Institute of Health. The institute did not have a role in the design of the study and collection, analysis and interpretation of data or in writing the manuscript.

\section{Availability of data and materials}

The data used and/or analyzed during the current study are available from the corresponding author on reasonable request.

\section{Authors' contributions}

MS and TB conceived and planned the study. MS, DL, MST, TY, TB and ET implemented the study. MS and TB did the analyses.MS drafted the manuscript. DL, MST, TY, TB and ET critically reviewed the manuscript. All authors gave input to the manuscript and read and approved the final version.

\section{Ethics approval and consent to participate}

The study protocol was ethically approved by the Ethical review board of Jimma University before the start of the study on February 5, 2015 with a reference number of: RPGC/691/07. Adequate explanation was given to each participant and informed consent was obtained before data collection. To keep anonymity of all data, no personal identifiers were used except unique ID number. So, unlinked anonymous method was used, where the study subjects and their blood samples were matched later during analyses without revealing any personal identifiers. Informed verbal consent was obtained from each study subjects prior to the administration of questionnaire after the purpose of the study was explained to respondents. The study participants were informed that they will have the right to refuse or discontinue participating in the research without any compromise in the service they are getting from the respective facilities. Finally, the study participants were given their laboratory results printed on a slip that has only their unique identifier. This trial is retrospectively registered on Pan African Clinical Trial Registration with unique identification number of PACTR202003465339638.

\section{Consent for publication}

This is not applicable as the study does not have individual person's data.

\section{Competing interests}

Authors do not have any competing interests.

The authors declare that they have no competing interests.

\section{Author details}

${ }^{1}$ Department of nutrition and dietetics, Jimma University, South West Ethiopia.

${ }^{2}$ Population Studies Centre, Brown University, Providence, USA.

${ }^{3}$ Department of Laboratory sciences, Jimma University, South West Ethiopia.

${ }^{4}$ Department of Internal Medicine, Jimma University, South West Ethiopia.

\section{References}

1. Islam SM, Purnat TD, Phuong NT, Mwingira U, Schacht K, Fröschl G. Non-communicable diseases (NCDs) in developing countries: a symposium report. Global Health. 2014 Dec 11;10:81. doi: 10.1186/s12992-014-0081-9.

2. Jakovljevic MB, Milovanovic O. Growing Burden of Non-Communicable Diseases in the Emerging Health Markets: The Case of BRICS. Front Public Health. 2015 Apr 23;3:65. doi: 10.3389/fpubh.2015.00065. eCollection 2015.

3. Young F, Critchley J, LJohnstone L, Unwin Globalization and the dual disease burden in sub-Saharan Africa. Diabetes Voice, June 2010; 55(1).

4. Young F, Critchley JA, Johnstone LK, Unwin NC. A review of co-morbidity between infectious and chronic disease in Sub Saharan Africa: TB and Diabetes Mellitus, HIV and Metabolic Syndrome, and the impact of globalization. Globalization and Health 2009,5 :9 doi:10.1186/1744-8603-5-9.

5. BeLue R, Okoror TA, Iwelunmor J, Taylor KD, Degboe AN, Agyemang C, Ogedegbe G.An overviewof cardiovascular risk factor burden in subSaharan African countries: a socio-cultural perspective. Global Health. 2009 Sep 22;5:10. doi: 10.1186/1744-8603-5-10.

Page $7 / 16$ 
6. WHO: The Global Burden of Disease: 2004 update. Switzerland

7. Estrada V, Martínez-Larrad MT, González-Sánchez JL, de Villar NG, Zabena C, Fernández C, Serrano-Ríos M. Lipodystrophy and metabolic syndrome in HIV-infected patients treated with antiretroviral therapy. 2006 Jul;55(7):940-5.

8. Alvarez C, Salazar R, Galindez J, Rangel F, Castaãeda ML, Lopardo G, Cuhna CA, Roldan Y, Sussman O, Gutierrez G, Cure-Bolt N, Seas C, Carcamo C, Castrillo M. Metabolic syndrome in HIV-infected patients receiving antiretroviral therapy in Latin America. Braz J Infect Dis. 2010 May-Jun;14(3):256-63.

9. Tran A, Gelaye B, Girma B, Lemma S, Berhane Y, Bekele T, Khali A, Williams MA. Prevalence of Metabolic Syndrome among Working Adults in Ethiopia.Int J Hypertens.2011;2011:193719. doi: 10.4061/2011/193719. Epub 2011 May 26.

10. Nshisso LD, Reese A, Gelaye B, Lemma S, Berhane Y, Williams MA. Prevalence of hypertension and diabetes among Ethiopian adults.Diabetes MetabSyndr.2012 Jan-Mar;6(1):36-41. doi: 10.1016/j.dsx.2012.05.005. Epub 2012 Jun 5.

11. Dunkley AJ, Charles K, Gray LJ, Camosso-Stefinovic J, Davies MJ, Khunti K. Effectiveness of interventions for reducing diabetes and cardiovascular disease risk in people with metabolic syndrome: systematic review and mixed treatment comparison meta-analysis. Diabetes Obes Metab. 2012 Jul;14(7):616-25. doi: 10.1111/j.1463-1326.2012.01571.x. Epub 2012 Feb 21.

12. van Namen M, Prendergast L, Peiris C.Supervisedlifestyle intervention for people with metabolic syndrome improves outcomes and reduces individual risk factors of metabolic syndrome: A systematic review and meta-analysis. 2019 Dec;101:153988. doi: 10.1016/j.metabol.2019.153988. Epub 2019 Oct 28.

13. Yamaoka K, Tango T. Effects of lifestyle modification on metabolic syndrome: a systematic review and meta-analysis. BMC Med.2012 Nov 14;10:138. doi: 10.1186/1741-7015-10-138.

14. Blackford K, Jancey J, Lee AH, James AP, Waddell T, Howat P. Home-based lifestyle intervention for rural adults improves metabolic syndrome parameters and cardiovascular risk factors: A randomized controlled trial.Prev Med.2016 Aug;89:15-22. doi: 10.1016/j.ypmed.2016.05.012. Epub 2016 May 16.

15. Sinaga M, Worku M, Yemane T, Tegene E, Wakayo T, Girma T, Lindstrom D, Belachew T. Optimal cut-off for obesity and markers of metabolic syndrome for Ethiopian adults. Nutr J. 2018 Nov 22;17(1):109. doi: 10.1186/s12937-018-0416-0.

16. The WHO STEPwise approach to noncommunicable disease risk factor surveillance. Last Updated: 26 January 2017. Available from: https://www.who.int/ncds/surveillance/steps/STEPS_Manual.pdf. Accessed on January 2020.

17. Getahun W, Gedif T, Tesfaye F. Regular Khat (Catha edulis) chewing is associated with elevated diastolic blood pressure among adults in Butajira, Ethiopia: a comparative study. BMC Public Health. 2010; 10:390. [PubMed: 20594361]

18. Waist Circumference and Waist-Hip Ratio Report of a WHO Expert Consultation GENEVA, 8-11 DECEMBER 2008. Avaialble from: https://apps.who.int/iris/bitstream/handle/10665/44583/9789241501491_eng.pdf;jsessionid=D3E0AACFF0CE01B24BCD3621BA528636?sequence=1.

19. Beilby J. Definition of Metabolic Syndrome: Report of the National Heart, Lung, and Blood Institute/American Heart Association Conference on Scientific Issues Related to Definition. Clin Biochem Rev. Aug 2004; 25(3): 195-198.

20. International Diabetes Federation. The IDF consensus worldwide definition of the Metabolic Syndrome, 2006. Available from: https://www.idf.org/elibrary/consensus-statements/60-idfconsensus-worldwide-definitionof-the- metabolic-syndrome.html. Accessed 12 Feb 2018.

21. Yadav R, Yadav RK, Khadgawat R, Pandey RM, Upadhyay AD, Mehta N.Randomized Controlled Trial of A 12-Week YogaBased (Including Diet) Lifestyle vs. Dietary Intervention on CardioMetabolic Risk Factors and Continuous Risk Score in Indian Adults with Metabolic Syndrı Behav Med.2020 Jan-Mar;46(1):9-20. doi: 10.1080/08964289.2018.1538098. Epub 2019 Jan 7.

22. Chaiyasoot K, Sarasak R, Pheungruang B, Dawilai S, Pramyothin P, Boonyasiri A, Supapueng O, Jassil FC, Yamwong P, Batterham RL. Evaluation of a 12week lifestyle education intervention with or without partialmeal replacement in Thai adults with obesity and metabolic syndrome: a randomized trial. Nutr Diabetes. 2018 Apr 25;8(1):23. doi: 10.1038/s41387-018-0034-0.

23. Kataria I, Chadha R, Pathak R. Dietary and lifestyle modification in metabolic syndrome: a review of randomized control trials in different population groups. Reviews in Health Care 2013; 4(4): 209-230

24. Azizi F, Mirmiran P, Momenan AA, et al. The effect of community-based education for lifestyle intervention on the prevalence of metabolic syndrome and its components: tehran lipid and glucose study. Int J Endocrinol Metab. 2013 Summer;11(3):145-53. doi: 10.5812/ijem.5443. Epub 2013 Jul 1.

25. Grave RD, Calugi S, Centis E, Marzocchi R, Ghoch ME, Marchesin G. Lifestyle modification in the management of the metabolic syndrome: achievements and challenges. Diabetes, Metabolic Syndrome and Obesity: Targets and Therapy 2010:3.https://doi.org/10.29328/journal.hodms.1001004

26. Bassi N, Karagodin I, Wang S, Vassallo P, Priyanath A, Massaro E, Stone NJ. Lifestyle modification for metabolic syndrome: a systematic review. Am J Med. 2014 Dec;127(12):1242.e1-10. doi: 10.1016/j.amjmed.2014.06.035. Epub 2014 Jul 5. PMID: 25004456.

27. Valmorbida LA, Borsatto AC, Feoli AM, Antunes MT, Breigeiron MK, Macagnan FE. Benefits of lifestyle modification on the metabolic syndrome. Fisioter Mov. 2013; 26(4): 835-43.

28. Ostman C, Smart NA, Morcos D, Duller A, Ridley W, Jewiss D. The effect of exercise training on clinical outcomes in patients with the metabolic syndrome: a systematic review and meta-analysis. Cardiovasc Diabetol.2017 Aug 30;16(1):110. doi: 10.1186/s12933-017-0590-y.

29. Pérez-Martínez P, Mikhailidis DP, Athyros VG, et al., . Lifestyle recommendations for the prevention and management of metabolic syndrome: an international panel recommendation. Nutr Rev. 2017 May; 75(5): 307-326.

30. Yang Y-M, Shin B-C, Son C, Ha I-H. An analysis of the associations between gender and metabolic syndrome components in Korean adults: a national cross-sectional study , BMC Endocrine Disorders , 2019; 19:67.

31. Bhanushali CJ1, Kumar K, Wutoh AK, Karavatas S, Habib MJ, Daniel M, Lee E. Association between Lifestyle Factors and Metabolic Syndrome among African Americans in the United States. J Nutr Metab. 2013;2013:516475. doi: 10.1155/2013/516475. Epub 2013 Jan 31.

Page $8 / 16$ 
32. Weng C1, Yuan H, Tang X, Huang Z, Yang K, Chen W, Yang P, Chen Z, Chen F. Age- and gender dependent association between components of metabolic syndrome and subclinical arterial stiffness in a Chinese population. Int J Med Sci. 2012;9(8):730-7. doi: 10.7150/ijms.4752. Epub 2012 Oct 16.

33. VanWormer JJ, Boucher JL, Sidebottom AC, Sillah A, Knickelbine T. Lifestyle changes and prevention of metabolic syndrome in the Heart of New Ulm Project. Prev Med Rep. 2017 Mar 29;6:242-245. doi: 10.1016/j.pmedr.2017.03.018. eCollection 2017 Jun.

34. Burini RC, Kano HT, Nakagaki MS, Frenhani PB, McLellan KCP. Behavioral factors of Abdominal Obesity and effects of lifestyle changes with Fiber Adequacy. New Insights Obes Gene Beyond. 2017; 1: 014-022.

35. Wadolowska L, Hamulka J, Kowalkowska J, et al., Changes in Sedentary and Active Lifestyle, Diet Quality and Body Composition Nine Months after an Education Program in Polish Students Aged 11ه12 Years: Report from the ABC of Healthy Eating Study. Nutrients, 03 Feb 2019,11(2). DOI: 3390/nu11020331 PMID: 30717465 PMCID: PMC6412996

36. Gharipour M, Sarrafzadegan N, Sadeghi M, Khosravi A, Hoseini M, Khosravi-Boroujeni H, Khaledifar A. The metabolic syndrome and associated lifestyle factors among the Iranian population. Adv Biomed Res. 2015 May 11;4:84. doi: 10.4103/2277-9175.156645. eCollection 2015.

37. Yang MH, Kang SY, Lee JA, Kim YS, Sung EJ, Lee KY, Kim JS, Oh HJ, Kang HC, Lee SY. The Effect of Lifestyle Changes on Blood Pressure Control among Hypertensive Patients. Korean J Fam Med. 2017 Sep;38(5):311-312. doi: 10.4082/kjfm.2017.38.5.311. Epub 2017 Sep 22.

38. Fazliana M, Liyana AZ, Omar A, Ambak R, Mohamad Nor NS, Shamsudin UK, Salleh NA, Aris T. Effects of weight loss intervention on body composition and blood pressure among overweight and obese women:. BMC Womens Health. 2018 Jul 19;18(Suppl 1):93. doi: 10.1186/s12905-018-0592-2.

39. Lee SB, Cho AR, Kwon YJ, Jung DH. Body fat change and 8-year incidence of hypertension: Korean Genome and Epidemiology Study. J Clin Hypertens (Greenwich). 2019 Dec;21(12):1849-1857. doi: 10.1111/jch.13723. Epub 2019 Oct 29.

40. Michishita R, Tanaka H, Kumahara H, Ayabe M, Tobina T, Yoshimura E, Matsuda T, Higaki Y, Kiyonaga A (2014) Effects of Lifestyle Modifications on Improvement in the Blood Lipid Profiles in Patients with Dyslipidemia. J Metabolic Synd 3: 150. doi: 10.4172/2167-0943.1000150

41. Akbari M, Lankarani KB, Naghibzadeh-Tahami A, Tabrizi R, Honarvar B, Kolahdooz F, Borhaninejad V, Asemi Z. The effects of mobile health interventions on lipid profiles among patients with metabolic syndrome and related disorders: A systematic review and meta-analysis of randomized controlled trials. Diabetes Metab Syndr. 2019 May - Jun;13(3):1949-1955. doi: 10.1016/j.dsx.2019.04.011. Epub 2019 Apr 12.

42. Sheng Z, Cao JY, Pang YC, Xu HC, Chen JW, Yuan JH, Wang R, Zhang CS, Wang LX, Dong J. Effects of Lifestyle Modification and Anti-diabetic Medicine on Prediabetes Progress: A Systematic Review and Meta-Analysis. Front Endocrinol (Lausanne). 2019 Jul 12;10:455. doi: 10.3389/fendo.2019.00455. eCollection 2019.

43. Swiger KJ ${ }^{1}$, Martin SS, Blaha MJ, Toth PP, Nasir K, Michos ED, Gerstenblith G, Blumenthal RS, Jones SR.Narrowingsex differences in lipoprotein cholesterol subclasses following mid-life: the very large database of lipids (VLDL-10B). J Am Heart Assoc. 2014 Apr 22;3(2):e000851. doi: 10.1161/JAHA.114.000851.

44. Lara M, Amigo H.Association between education and blood lipid levels as income increases over a decade: a cohort study. BMC Public Health.2018 Feb 27;18(1):286. doi: 10.1186/s12889-018-5185-3.

45. Leung AWY, Chan RSM, Sea MMM, Woo J.An Overview of Factors Associated with Adherence to Lifestyle Modification Programs for Weight Management in Adults. Int J Environ Res Public Health.2017 Aug 16;14(8). pii: E922. doi: 10.3390/ijerph14080922.

46. Jembere GB, Cho Y, Jung M. Decomposition of Ethiopian life expectancy by age and cause of mortality; 1990-2015. PLoS One. 2018 Oct 3; 13 (10):e0204395. doi: 10.1371/journal.pone.0204395. eCollection 2018.

47. Central Statistical Authority [Ethiopia] and ORC Macro. 2001. Ethiopia Demographic and Health Survey. Addis Ababa, Ethiopia and Calverton, Maryland, USA: Central Statistical Authority and ORC Macro, 2000.

48. Central Statistical Agency [Ethiopia] and ORC Macro. Ethiopia Demographic and Health Survey 2005. Addis Ababa, Ethiopia and Calverton, Maryland, US A: Central Statistical Agency and ORC Macro, 2006.

49. Ethiopian Demographic and Health Survey. Addis Ababa, Ethiopia and Calverton Maryland, USA.; 2011.

50. Ethiopian Demographic and Health Survey. Addis Ababa, Ethiopia and Calverton Maryland, USA.; 2016

51. Ethiopian Demographic and Health Survey . Addis Ababa, Ethiopia and Calverton Maryland, USA.; 2019

52. DeBoer MD, Lima AA, Oría RB, Scharf RJ, Moore SR, Luna MA, Guerrant RL. Early childhood growth failure and the developmental origins of adult disease: do enteric infections and malnutrition increase risk for the metabolic syndrome? Nutr Rev.2012 Nov;70(11):642-53. doi: 10.1111/j.17534887.2012.00543.x.

53. Yarinbab TE, Alemseged F. Prevalence and Determinants of Modifiable Risk Factors for Chronic Non-Communicable Diseases among Adults in MizanAman Town, Ethiopia: A Community Based Cross Sectional Study. JOJ Pub Health, 2018;3(5): 1-8.

54. Abebe SM, Andarge G, Shimekaa A, et al. The prevalence of non-communicable diseases in northwest Ethiopia: survey of Dabat Health and Demographic Surveillance System. Abebe SM, et al. BMJ Open 2017;7:e 015496. doi:10.1136/bmjopen-2016-015496

55. Gebreyes YF, Goshu DY, Geletew TK, Argefa TG, Zemedu TG, Lemu KA et al. Prevalence of high bloodpressure, hyperglycemia, dyslipidemia, metabolic syndrome and their determinants in Ethiopia: Evidences from the National NCDs STEPS Survey, 2015. PLoS One. 2018 May 9;13(5):e0194819. doi: 10.1371/journal.pone.0194819. eCollection 2018.

\section{Tables}

Table 1. Intervention protocol for nutrition and life style behaviour change communication (BCC) among Employees of Jimma University, Ethiopia 


\begin{tabular}{|c|c|c|c|c|}
\hline Key action(message) & Strategy of intervention & Responsible & Frequency & Compliance Parameter \\
\hline $\begin{array}{l}\text { Consumption of Diversified Diet (The six food groups) } \\
\text { Exercise(Moderate intensity exercise of } 30 \text { minutes at least for } 3 \\
\text { days a week) } \\
\text { Life styles (no smoking, alcohol drinking, no khat chewing, } \\
\text { getting adequate sleep of } 6-8 \text { hours, not sitting /reclining for } \\
\text { long time) } \\
\text { Drinking more water } \\
\text { Metabolic syndrome and its risk factors, consequences }\end{array}$ & $\begin{array}{l}\text { leaflet with key message(in Amharic) } \\
\text { metabolic syndrome and dietary and life style } \\
\text { behaviours } \\
\text { Reminders (key mottos of the behaviours were sent by } \\
\text { text message (Group e-mail as applicable) }\end{array}$ & $\begin{array}{l}\text { Research } \\
\text { Team } \\
\text { members } \\
\text { Research } \\
\text { Team } \\
\text { Members }\end{array}$ & $\begin{array}{l}\text { Once a month } \\
\text { Saturday once } \\
\text { in } 15 \text { days }\end{array}$ & $\begin{array}{l}\text { Number of intervention } \\
\text { participants who received } \\
\text { the leaflet } \\
\text { \&requency } \\
\text { \& attendance } \\
\text { Frequency }\end{array}$ \\
\hline
\end{tabular}

Table 2. Baseline background characteristics of intervention and control groups, Jimma University, Ethiopia

\begin{tabular}{lccc}
\hline Variables & $\mathrm{n}$ & Intervention $(\mathrm{n}=112)$ & Control(n=112) \\
\cline { 3 - 4 } & & Mean( $\pm \mathrm{sd})$ & Mean $( \pm \mathrm{sd})$ \\
\hline Sex: $\mathrm{n}(\%)$ & & & \\
$\quad \mathrm{M}$ & 106 & $63.0(50.9)$ & $55.0(43.8)$ \\
$\mathrm{F}$ & 118 & $49.0(49.1)$ & $57.0(56.3)$ \\
Age $(\mathrm{Yrs})$ & 224 & $36.9(9.0)$ & $37.7(10.0)$ \\
\hline FBS $(\mathrm{mg} / \mathrm{dl})$ & 224 & $97.1(21.6)$ & $102.4(39.6)$ \\
\hline HDL $(\mathrm{mg} / \mathrm{dl})$ & 224 & $58.7(28.7)$ & $68.3(63.4)$ \\
\hline Total Cholesterol $(\mathrm{mg} / \mathrm{dl})$ & 224 & $182.3(38.8)$ & $182.6(52.4)$ \\
\hline TG $(\mathrm{mg} / \mathrm{dl})$ & 224 & $147.8(102.3)$ & $148.5(84.7)$ \\
\hline LDL $(\mathrm{mg} / \mathrm{dl})$ & 224 & $94.0(43.0)$ & $84.6(77.3)$ \\
\hline Systolic Blood Pressure $(\mathrm{mm} \mathrm{Hg})$ & 224 & $117.6(11.6)$ & $118.4(13.9)$ \\
\hline Diastolic Blood Pressure $(\mathrm{mm} \mathrm{Hg})$ & 224 & $77.9(9.4)$ & $77.91(9.1)$ \\
\hline Waist Circumference $(\mathrm{cm})$ & 224 & $86.3(12.8)$ & $85.5(12.8)$ \\
\hline Body fat percent $(\%)$ & 224 & $31.4(11.2)$ & $31.5(10.9)$ \\
\hline Body mass index $\left(\mathrm{kg} / \mathrm{m}^{2}\right)$ & 224 & $25.3(4.9$ & $25.0(5.2)$ \\
\hline Weight(kg) & 224 & $67.9(13.4)$ & $67.0(13.3)$ \\
\hline
\end{tabular}

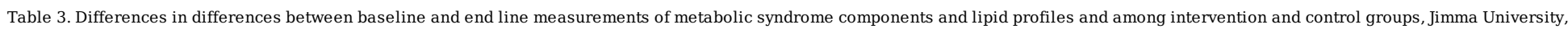
Ethiopia

\begin{tabular}{|c|c|c|c|c|c|c|c|c|}
\hline \multirow[t]{3}{*}{ Metabolic syndrome components and lipid profile } & \multicolumn{3}{|c|}{ Intervention } & \multicolumn{3}{|c|}{ Control } & \multirow{2}{*}{\multicolumn{2}{|c|}{$\begin{array}{l}\text { Difference in } \\
\text { Differences }\end{array}$}} \\
\hline & \multirow{2}{*}{$\begin{array}{l}\text { Baseline } \\
\text { Mean( } \pm \mathrm{SD})\end{array}$} & \multirow{2}{*}{$\begin{array}{l}\text { End line } \\
\text { Mean }( \pm \mathrm{SD})\end{array}$} & \multirow{2}{*}{$\begin{array}{l}\text { Difference } \\
(\mathrm{BL}-\mathrm{EL}) \\
\text { Mean }( \pm \mathrm{SD})\end{array}$} & \multirow{2}{*}{$\begin{array}{l}\text { Baseline } \\
\text { Mean( } \pm \text { SD) }\end{array}$} & \multirow{2}{*}{$\begin{array}{l}\text { End line } \\
\text { Mean }( \pm S D)\end{array}$} & \multirow{2}{*}{$\begin{array}{l}\text { Difference } \\
(B L-E L) \\
\text { Mean }( \pm S D)\end{array}$} & & \\
\hline & & & & & & & $\operatorname{Mean}( \pm \mathrm{SE})$ & $P$ \\
\hline Waist Circumference $(\mathrm{cm})$ & $86.3(12.8)$ & $80.8(12.7)$ & $5.6(7.2)$ & $85.5(12.7)$ & $86.2(12.8)$ & $-0.7(5.9)$ & $6.3(1.7)$ & $<0.001$ \\
\hline Systolic BP(mmHg) & $117.8(11.8)$ & 107.8(15.0) & $10.0(12.7)$ & $118.2(13.8)$ & $114.2(16.3)$ & $4.0(11.9)$ & $6.0(1.7)$ & $<0.001$ \\
\hline Diastolic BP(mmHg) & $77.8(9.4)$ & $70.9(9.4)$ & $6.9(6,2)$ & $77.9(9.1)$ & $74.5(9.8)$ & $3.4(7.7)$ & $3.6(1.1)$ & 0.001 \\
\hline T. Cholesterol(mg/dl) & $182.3(38.8)$ & $139.2(35.4)$ & $43.0(35.3)$ & $182.6(52.4)$ & $170.3(50.4)$ & 12.2(70.9) & $30.7(7.5)$ & $<0.001$ \\
\hline Triglyceride (mg/dl) & $147.8(102.3)$ & $98.6(54.7)$ & $49.5(83.1)$ & 148.5(84.7) & $154.4(87.7)$ & $-6(10.6 .1)$ & $55.5(12.9)$ & $<0.001$ \\
\hline $\mathrm{HDL}(\mathrm{mg} / \mathrm{dl})$ & $58.7(28.7)$ & $42.5(11.5)$ & $16.4(29.8)$ & $68.3(63.4)$ & $49.5(17.8)$ & $18.8(64.0)$ & $-2.4(6.7)$ & 0.717 \\
\hline $\mathrm{LDL}(\mathrm{mg} / \mathrm{dl})$ & $94.0(43.0)$ & $76.9(27.9)$ & $16.8(43.2)$ & $84.6(77.3)$ & $89.7(32.4)$ & $-5.1(83.5)$ & $21.9(8.9)$ & 0.015 \\
\hline Fasting Blood Sugar(mg/dl) & $97.1(21.4)$ & $78.8(21.9)$ & $18.4(28.8)$ & 102.3(38.9) & $106.2(37.1)$ & $-3.9(24.8)$ & $22.2(3.6)$ & $<0.001$ \\
\hline Weight(kg) & $67.9(13.4)$ & $65.9(12.3)$ & $2.0(4.7)$ & $67.0(13.3)$ & $65.4(13.1)$ & $1.6(4.7)$ & $0.4(0.6)$ & 0.494 \\
\hline BMI & $25.3(4.9$ & $24.5(4.6)$ & $0.7(1.7)$ & $67.0(13.3)$ & $24.3(5.1)$ & $0.6(1.7)$ & $0.1(0.2)$ & 0.565 \\
\hline
\end{tabular}

$B L=$ Baseline. $E L=$ End line,$B P=$ Blood Pressure, $S E=$ Standard error, $S D$ - Standard Deviation.

Table 4. Multivariable linear regression model predicting the mean baseline to end line difference in the differences in the components of metabolic syndrome that dependent on physical measurements of study participants, Jimma university, Ethiopia 


\begin{tabular}{|c|c|c|c|}
\hline \multirow[t]{3}{*}{ Variables } & Differences in differences of Waist circumference & and Blood pressure between & Baseline end line (Baseline - End line) \\
\hline & $\begin{array}{l}\text { Waist Circumference } \\
(\mathrm{cm})\end{array}$ & $\begin{array}{c}\text { Systolic BP } \\
(\mathrm{mmHg})\end{array}$ & $\begin{array}{l}\text { Diastolic BP } \\
(\mathrm{mmHg})\end{array}$ \\
\hline & $\beta(95 \% \mathrm{CI})$ & $\beta(95 \% \mathrm{CI})$ & $\beta(95 \% \mathrm{CI})$ \\
\hline Sex & $2.0(2.1,6.1)$ & $1.6(-6.0,9.3)$ & $0.8(-4.8,6.4)$ \\
\hline \multicolumn{4}{|l|}{ Male } \\
\hline \multicolumn{4}{|l|}{ Female (Ref.) } \\
\hline Age (Yrs) & $0.2(0.0,0.4)$ & $-0.1(-0.4,0.3)$ & $0.1(-0.1,0.4)$ \\
\hline Monthly income & $-2.0(-7.4,3.3)$ & $9.2(-0.8,19.3)$ & $5.4(-1.9,12.8)$ \\
\hline High income & $0.6(-3.4,4.5)$ & $1.5(-6.0,8.9)$ & $0.0(-5.5,5.5)$ \\
\hline \multicolumn{4}{|l|}{ Medium income } \\
\hline \multicolumn{4}{|l|}{ Low(Ref.) } \\
\hline Educational Status & $2.4(-1.5,6.4)$ & $5.1(-2.2,12.5)$ & $-0.2(-5.6,5.2)$ \\
\hline High School and below(Ref.) & $2.7(-2.1,7.5)$ & $-4.9(-13.9,4.2)$ & $-4.1(-10.8,2.5)$ \\
\hline \multicolumn{4}{|l|}{ Diploma } \\
\hline \multicolumn{4}{|l|}{ Degree and above } \\
\hline Intervention & $6.1(4.2,8.9)^{* * *}$ & $6.5(3,1,9.9)^{* *}$ & $4.2(2.1,6.4)^{* *}$ \\
\hline \multicolumn{4}{|l|}{ Yes } \\
\hline \multicolumn{4}{|l|}{ Control(Ref.) } \\
\hline Baseline body fat percent & $0.1(-0.1,0.3)$ & $-0.1(-0.5,0.2)$ & $-0.2(-0.3,-0.1) *$ \\
\hline
\end{tabular}

Parameters adjusted for Number of days of Moderate intensity exercise in a week, Hours of sleep in a day and Takes break afterlong hours of sitting Maximum Variance inflation factor in all models $=4.2$.

Ref. :reference category.

$* * * P<0.001, * P<0.05$.

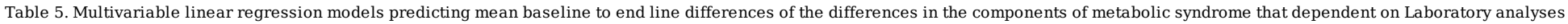
of blood sample of study participants, Jimma University, Ethiopia

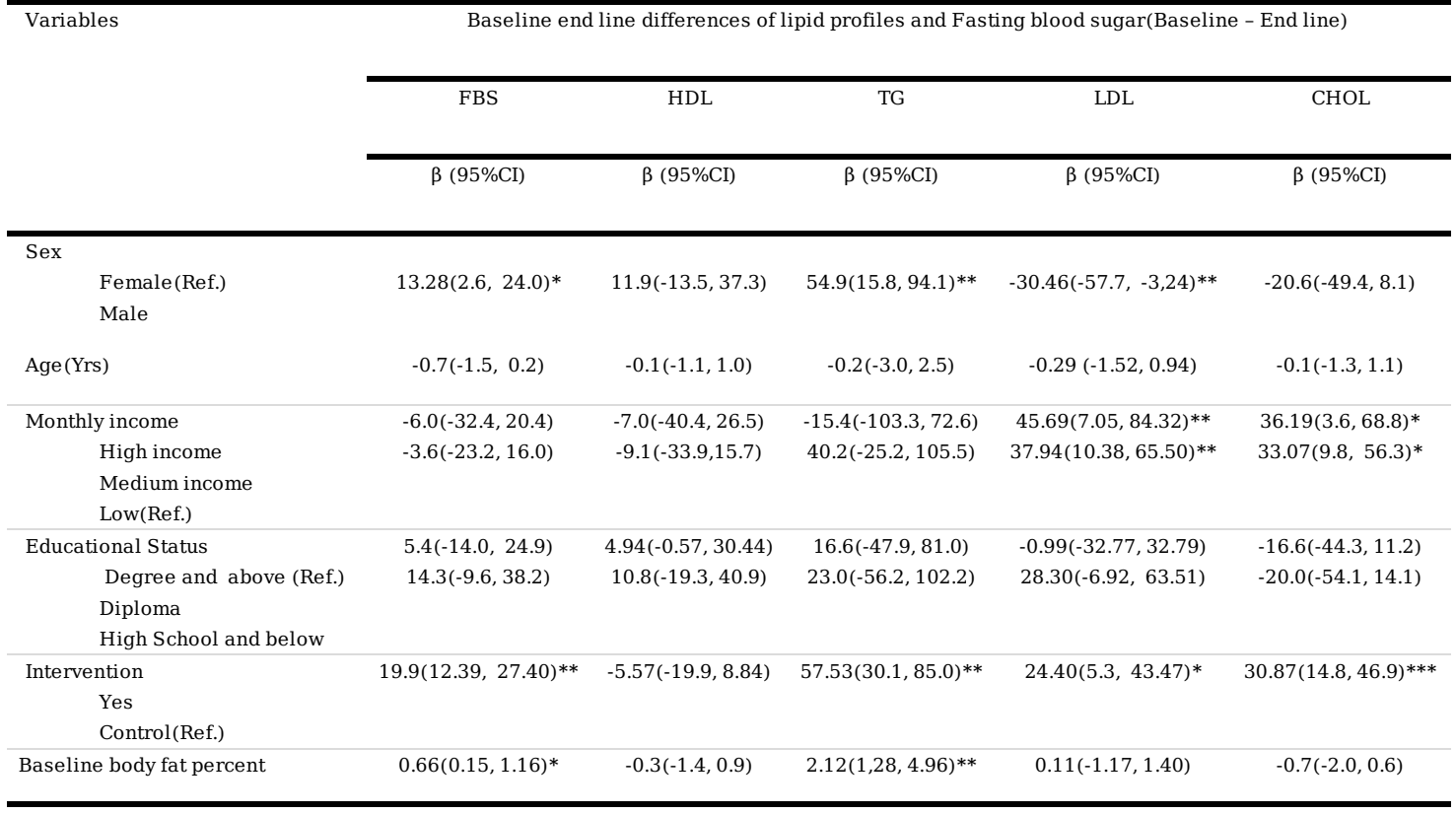

Parameters adjusted for number of days of moderate intensity exercise in a week, hours of sleep in a day and Takes break after long hours of sitting

Maximum Variance inflation factor in all models $=4.2$.

$T G=$ Triglyceride, HDL: high density Lipoprotein. LDL: low density lipoprotein, T.Chol: Total Cholesterol, FBS: Fasting blood sugar. ${ }^{* * P}<0.001$, $* * P<0.01, * P<0.05$.

Table 6. Multivariable logistic regression model predicting the likelihood of having metabolic syndrome at the end of the intervention of study participants, Jimma University, Ethiopia 


\begin{tabular}{|c|c|c|c|c|c|}
\hline \multirow[t]{2}{*}{ Predictors } & \multirow[t]{2}{*}{$\beta$} & \multirow[t]{2}{*}{$\mathrm{RR}$} & \multicolumn{2}{|c|}{ 95\% C.I. } & \multirow[t]{2}{*}{$P$} \\
\hline & & & Lower & Upper & \\
\hline \multicolumn{6}{|l|}{ Sex } \\
\hline Male & 2.32 & 10.19 & 2.60 & 39.84 & 0.0010 \\
\hline Female & & 1.00 & & & \\
\hline Age (Years) & 0.05 & 1.06 & 1.00 & 1.11 & 0.0400 \\
\hline \multicolumn{6}{|l|}{ Intervention } \\
\hline No & 2.00 & 7.42 & 3.00 & 18.38 & $<0.0001$ \\
\hline Yes & & 1.00 & & & \\
\hline \multicolumn{6}{|l|}{ Monthly income Tertile } \\
\hline Low & & 1.00 & & & \\
\hline Medium & -0.28 & 0.75 & 0.16 & 3.54 & 0.7190 \\
\hline High & -0.27 & 0.76 & 0.22 & 2.66 & 0.6710 \\
\hline \multicolumn{6}{|l|}{ Educational Status } \\
\hline Degree and above & -0.07 & 0.94 & 0.23 & 3.79 & 0.9250 \\
\hline Diploma & 0.15 & 1.16 & 1.08 & 1.24 & $<0.0001$ \\
\hline High School or below & & 1.00 & & & \\
\hline Baseline fat percent & 0.15 & 1.16 & 1.08 & 1.24 & $<0.0001$ \\
\hline
\end{tabular}

Hosmer Lemeshaw ( $P=0.068$ ), Maximum Standard error $=0.790$

AOR-Adjusted odds ratio, $C I=$ Confidence Interval.

\section{Figures}

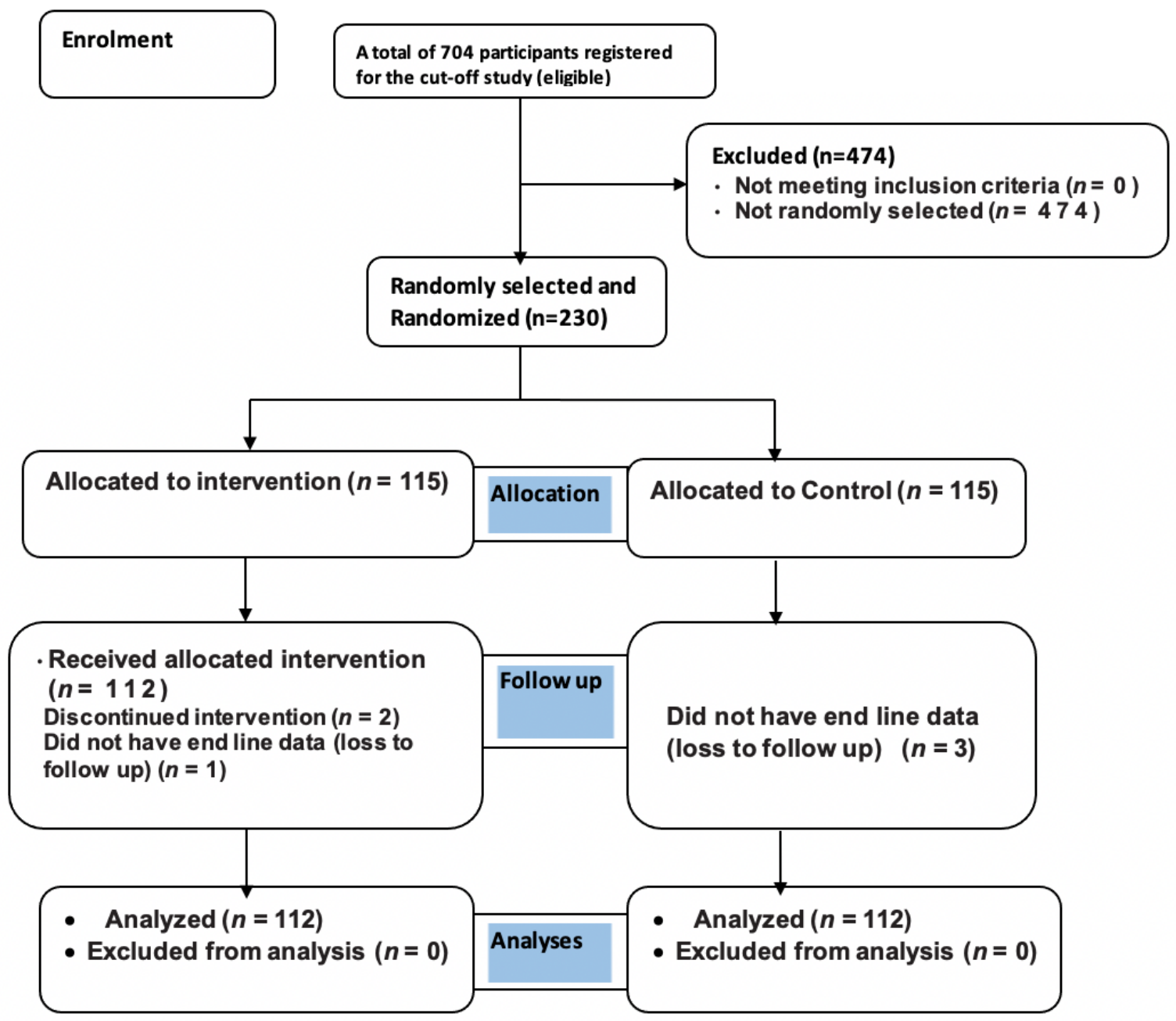

Figure 1

Trial flow diagram for the effect of behaviour change communication on metabolic syndrome an its markers among workers of Jimma University, Ethiopia 


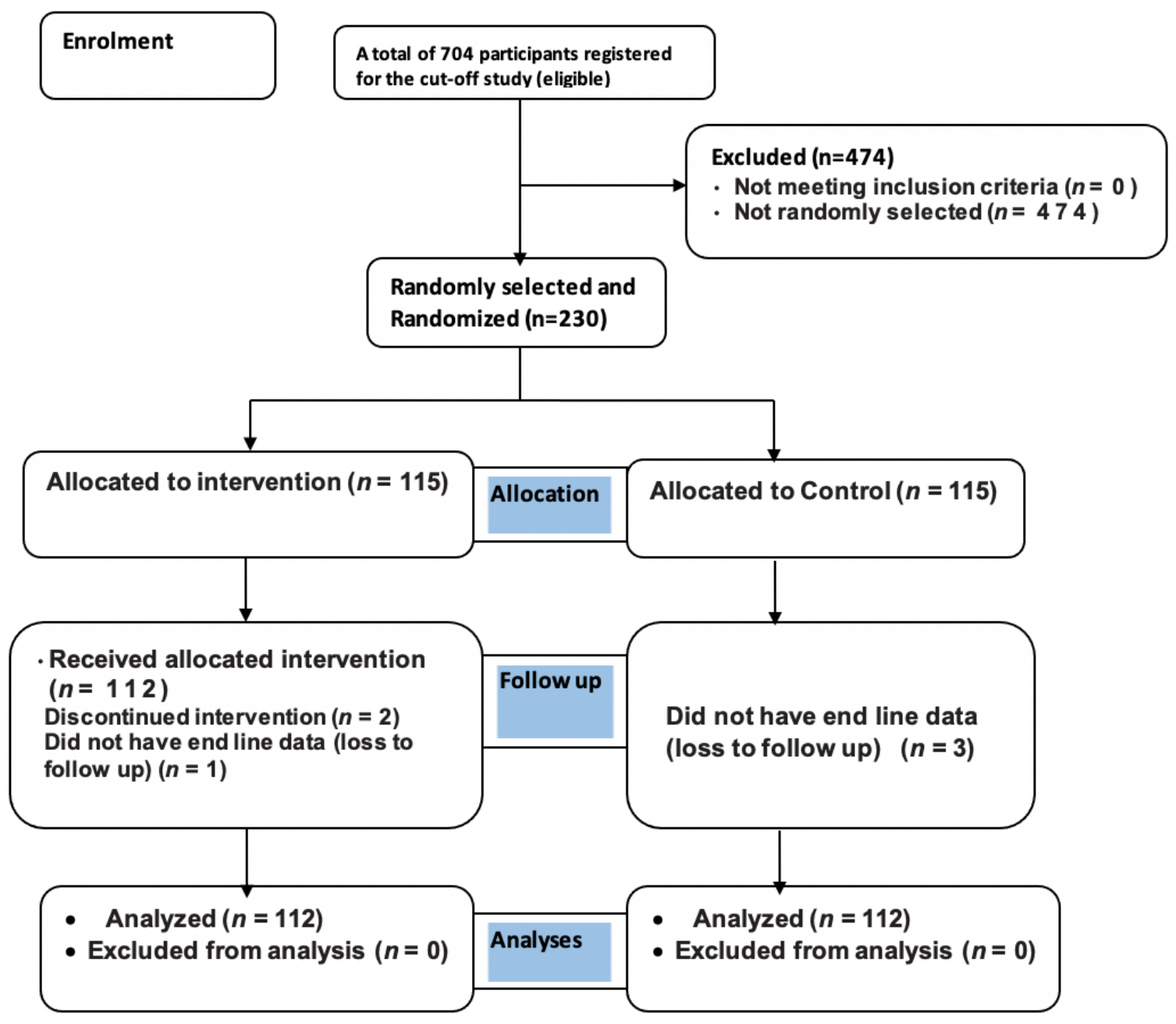

Figure 1

Trial flow diagram for the effect of behaviour change communication on metabolic syndrome an its markers among workers of Jimma University, Ethiopia 


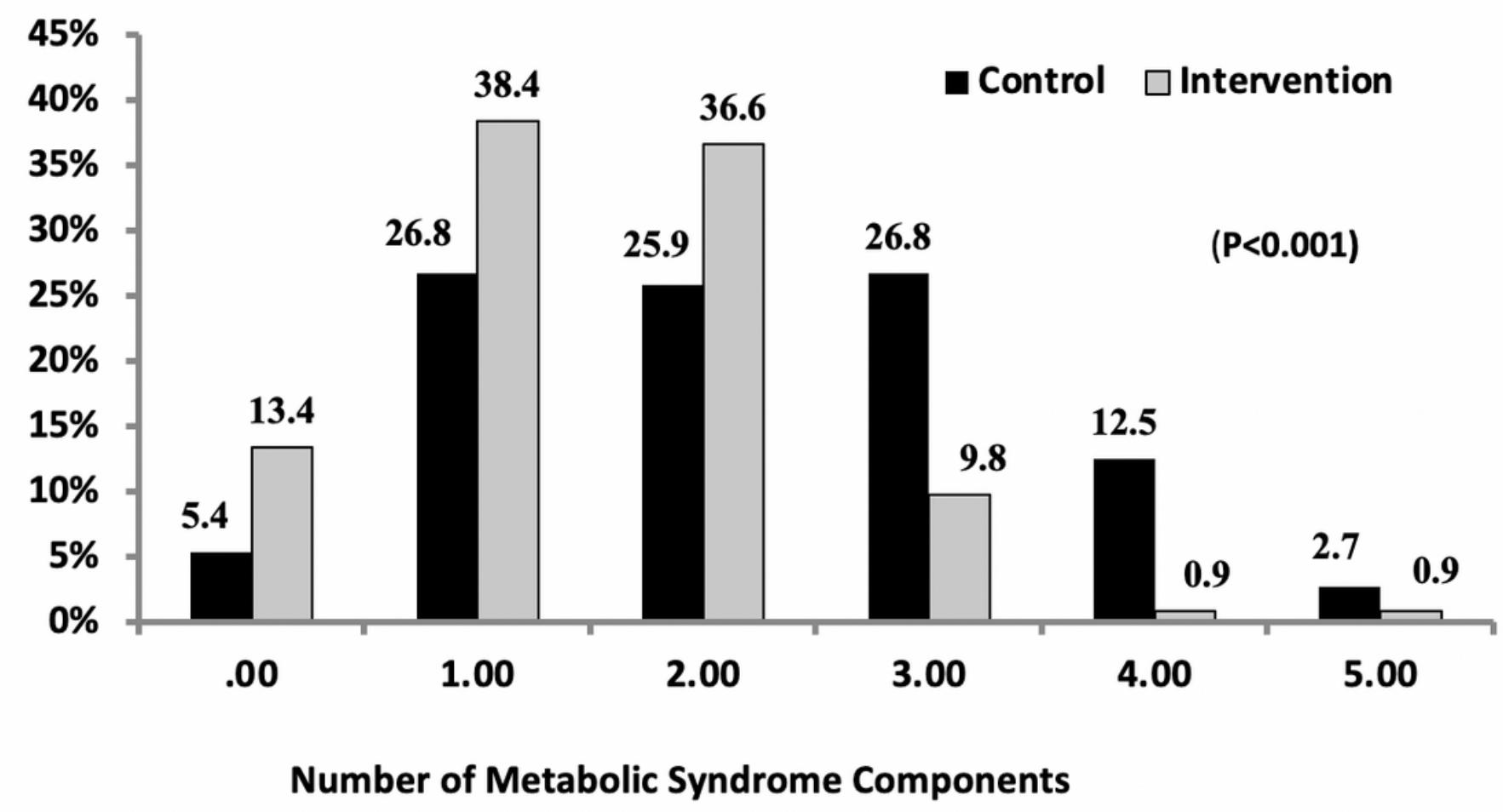

Figure 2

Proportion of study participants with different components of metabolic syndrome in the intervention and control groups at the end line, Jimma University, Ethiopia

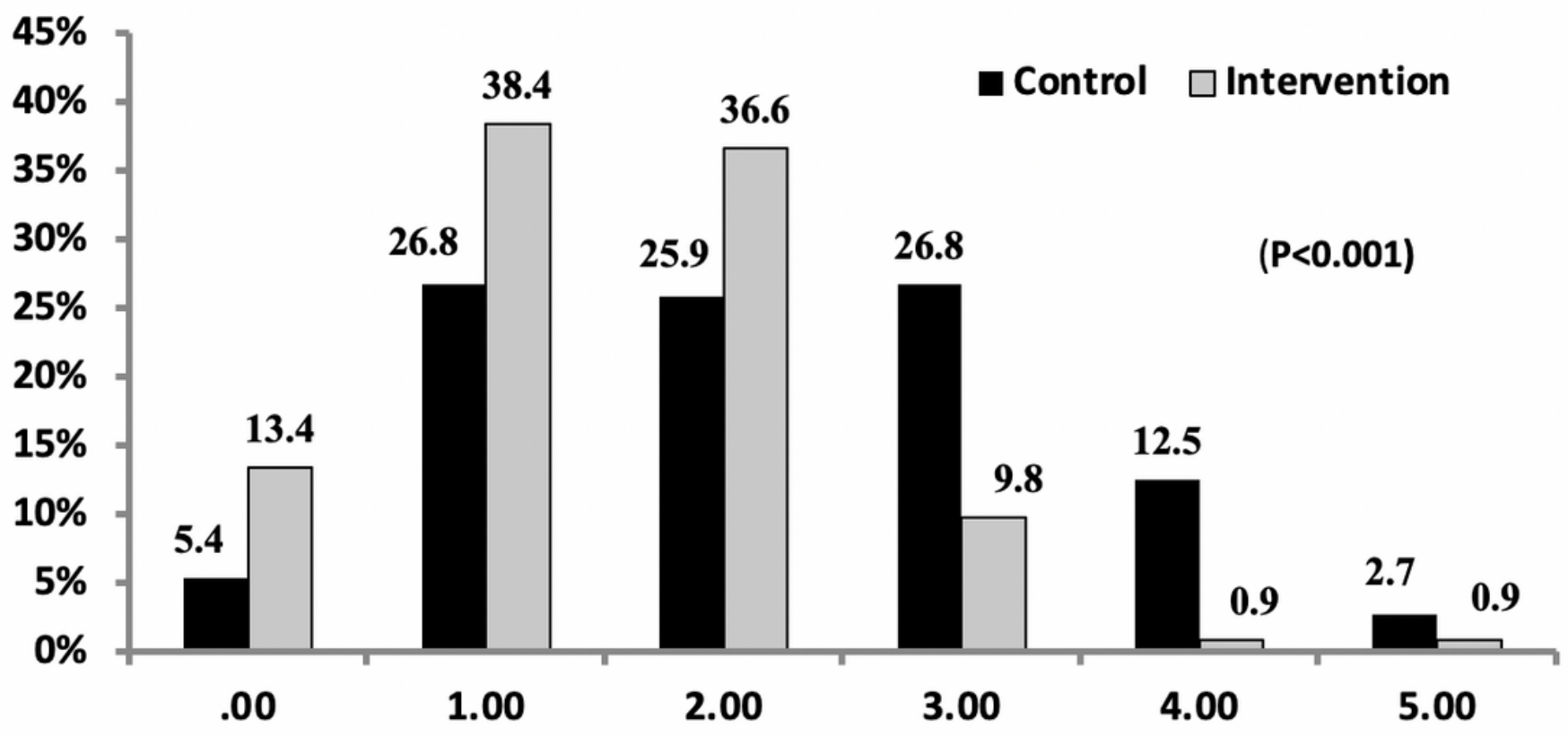

Number of Metabolic Syndrome Components 
Proportion of study participants with different components of metabolic syndrome in the intervention and control groups at the end line, Jimma University, Ethiopia

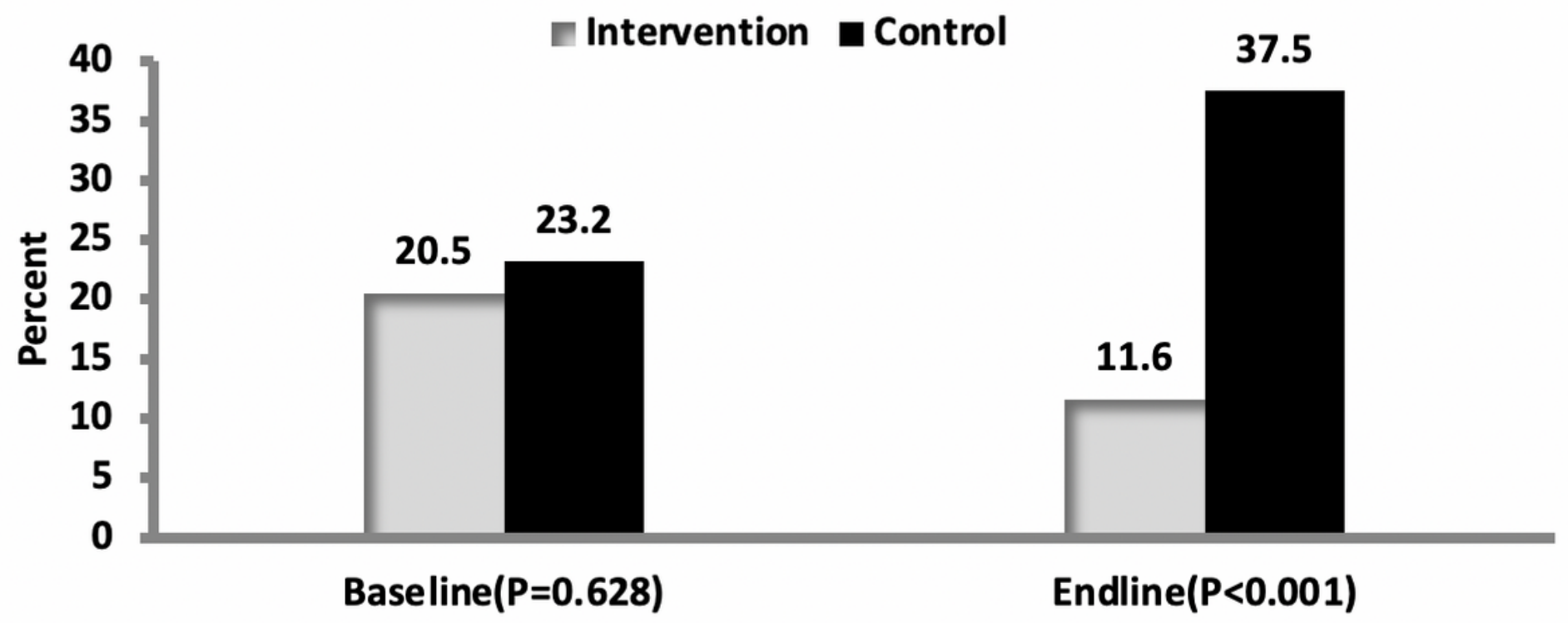

Figure 3

Baseline and endline differences in the proportion of metabolic syndrome among intervention and control groups, Jimma Universty, Ethiopia

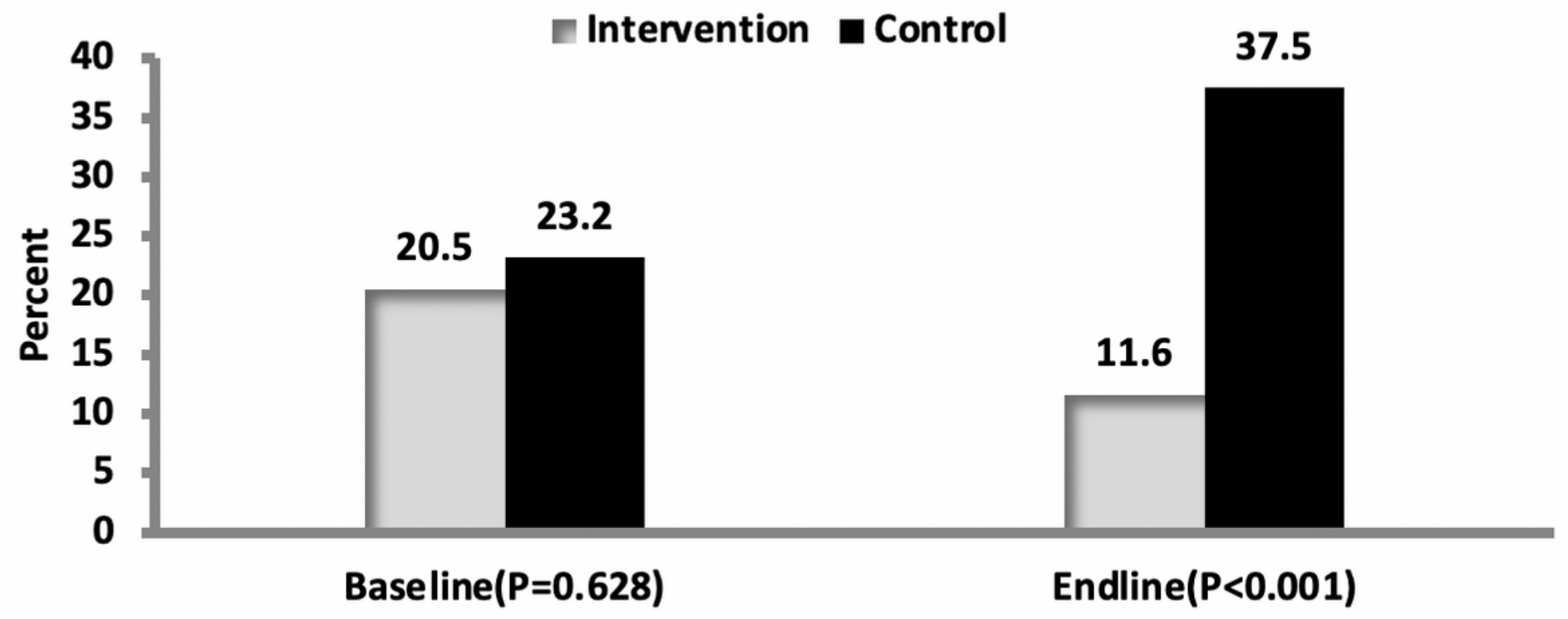

Figure 3

Baseline and endline differences in the proportion of metabolic syndrome among intervention and control groups, Jimma Universty, Ethiopia 


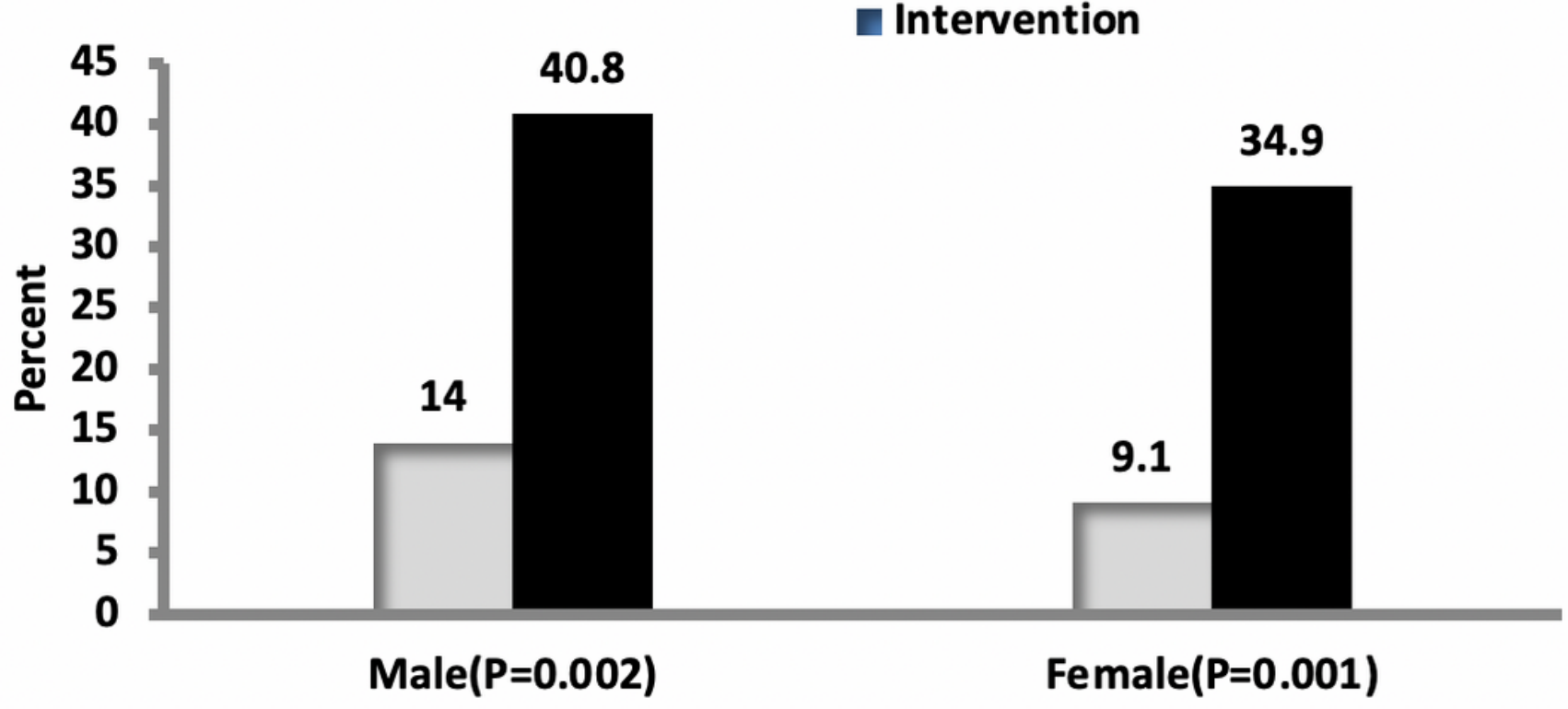

Figure 4

Prevalence of metabolic syndrome between intervention and control groups at the end line by sex, Jimma University southwest Ethiopia

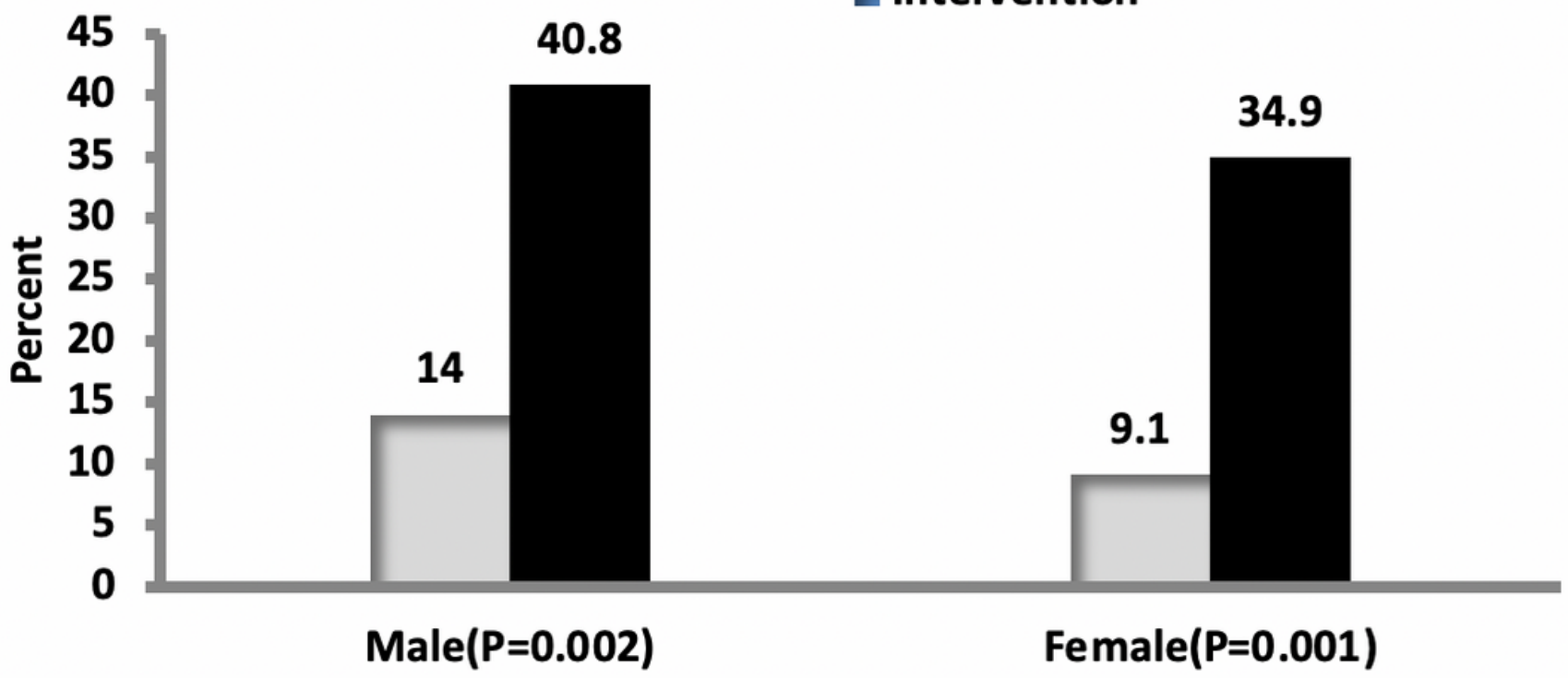

Figure 4

Prevalence of metabolic syndrome between intervention and control groups at the end line by sex, Jimma University southwest Ethiopia 